\title{
The Influence of Niche Strategy on the Internationalization of Chinese SMEs
}

\author{
Zhongwei $\mathrm{Cao}^{1, \mathrm{a} *}$ Jiang $\mathrm{Xu}^{2, \mathrm{~b}}$ Jingwei $\mathrm{Hu}^{3, \mathrm{a}}$ \\ ${ }^{1}$ Department of Applied Mathematics, Jilin University of Finance and Economics, Changchun \\ 130117, P.R.China \\ ${ }^{2}$ School of Econimics and Management, Changchun University of Technology, Changchun 130000, \\ P.R.China \\ a Caozw963@sina.com, bxujiang_1976@163.com, chujingwei123@163.com
}

Keywords: Niche; Niche Strategy; Internationalization

\begin{abstract}
Small and medium-sized enterprises (SMEs) play an important role in the national economy. However, researches of their internalization behavior are few, especially from the perspective of Niche. Based on the literature review, this paper puts forward the concept of Niche Strategy, which is to subdivide the market into multiple subsegments and exploit potential benefits for enterprises in different subsegments. Niche Transfer Strategy ensures the value of Niche Strategy. Niche Strategy is applicable, feasible and sustainable for SMEs.
\end{abstract}

\section{Introduction}

At present, SMEs play an important role in the national economy. In order to achieve their own industrial upgrading and the increase of added value, these enterprises actively pursue high profits and continue to explore the international market. Moreover, with the gradual change in the trend of global production, enterprises in various countries are competing to find production bases with low manufacturing costs, so that industries transfer to low cost countries, prompting enterprises to form a trend of foreign investment.

Because of their high mobility and flexibility, SMEs have already gone abroad to begin their international operations, fully demonstrating their resilience and adaptability. However, in the context of global mergers and acquisitions becoming more common and large-scale enterprises, the internationalization of SMEs has faced the challenge of upgrading and transformation. With the development of the internationalization of enterprises, many enterprises know little about the laws and decrees of the investment areas or ignore the new management issues arising from transnational operation, which leads to inefficiency in management and failure to meet the planned objectives. These factors have seriously impeded the development of SMEs in China. In this case, it has become the focus of academia and business community that in the face of different cultures and situations how to develop the management strategies and direction of the overseas subsidiaries to do not deviate from the overall objectives of the parent company and to integrate the resources of the parent company to maximize the profit. Therefore, exploring the specific, critical and operational factors affecting the internationalization of SMEs has become the key to the success of SMEs' internationalization. Therefore, Niche market opportunities have an important impact on the internationalization of SMEs.

\section{Literature Review}

The American naturalist J.Grinnel first proposed the term of niche. He believes that in the same region, two ethnic groups, which are very similar to food types, cannot maintain a long-term balance in quantity, and there must be one ethnic group better than the other, because the two communities are bound to compete for the same resources. There are many studies on niche market strategies, but there are few studies on niche market opportunities, although scholars agree that the niche market is 
full of opportunities (Akgün et al, 2007) [1].He believes that niche market opportunities are the market opportunities for enterprises to develop based on certain target customers. In this market, the company can provide products that are more in line with the customers' needs than other manufacturers. It can enhance the added value of the product and ensure the higher marginal profit of the enterprise (market nicher). Niche market opportunities are the opportunities which strong competitors ignore but the small businesses can see. Nisula et al (2018) [2] put forward the concept of niche market opportunity by studying the relationship between niche and performance, that is, niche market opportunity is the opportunity provided by the market that can match the resources and capabilities of the enterprise with the products and services that can be produced. This opportunity ensures that the capabilities of enterprises are not dissipated, the resources of enterprises are not abused, and the market efficiency and performance outputs of enterprises are guaranteed. Kale et al. (2002) [3]study the niche market from the entrepreneurial perspective. They believe that niche market opportunity is the opportunity offered by a market, that is, as a marketing strategy which is in order to avoid a positive conflict with a large enterprise with strong competitive power and competitive advantage, the enterprise chooses a small market as its target market which is ignored by the large enterprises, needs has not yet been met, has weak strength and has a profit base. This explanation provides a comprehensive exposition of the essence of niche market opportunities. As the opportunity provided by the "gap market", the adoption of niche market opportunities is mainly based on the following considerations: The first is to avoid market competition with large enterprises and select the market that they ignore, do not want to do or do not do as own business scope; The second is to reduce the scope of business, focus on a narrow scope of business, and strive to form a unique advantage; The third is to concentrate the niche business and build niche barriers. Kale et al (2002) defines niche market opportunities as a narrow market opportunity that enterprises search for to meet specific customer needs. He believes that this opportunity comes from the continuous segmentation and integration of the target market, emphasizing the specialization and production when enterprises seek niche market opportunities.

Based on the above analysis, this paper defines the niche strategy as: compared with the traditional market, it is a strategy that refines the market into multiple subsegments and can be exploited for the enterprise in different segments as well as bring potential benefits for the enterprise.

\section{Niche Transfer Strategy}

Patel and Terjesen (2011) [4] suggests in his study that enterprises must look at the position where the enterprise is now, identify the present position, carefully consider both the external and external opportunities, and examine the potential weaknesses and threats to identify the strategies that may be considered next. Enterprises must take the core things as the foundation, inspect the saturation state of the niche, and choose the next feasible strategy. Based on these principles, sensitized by the various strategies environment, Mintzberg concluded the following five stages of strategy:

(1) find out the core affair

Reymen et al. (2015) [5]believes that organizational strategy must be focused on a specific point, that is, the core business of the enterprise, in order to find out the appropriate business strategy at each stage.

The first is the upstream strategy. When all the users need the upstream basic products, the important strategy is to expose and sell the increasing variety of raw materials. Next is the middle reaches strategy, which assembles many single products into products that consumers need. Finally, the downstream strategy is to diversify products from the middle reaches and distribute products to retail consumers with specific channels.

(2) resolution of core affairs

First of all, it is a functional strategy to identify and link with the core business models of the company from the value chain. Specifically, there are open source strategies, which is related to procurement, personnel and finance, to meet core business needs through strengthening related resources. Process strategy is related to process development, production and operation strategy. The design strategy is product research and development strategy. Support strategy namely is related to 
regulations, control and training strategies.

The second is differentiation strategy, which can be differentiated from quality, design, support, impression and price, so that consumers can recognize differences and then be separated from competitors in the market. Including: 1) Price difference strategy: the standard product design makes the price of the product cheaper, which is essentially cheap, using the concept of cost leading, such as poor raw materials. But it is often accompanied by poor quality and other negative effects. 2) The strategy of image differentiation is to create the mind position, give the image, create value and make it different (Because of creating image through advertising and promotion, it is accompanied by higher prices and positioning). 3) Support differentiated strategy: for potential customers, products are complex clusters that satisfy value. Use complementary product support to create differentiated processes to provide products or services to meet customer value. 4) Quality differentiation strategy: to make the quality of the product better than the competitor, the product can indeed achieve the benefits, and continue to work for a period of time, and can be better and faster, which means the enterprise owns good production process and source of raw materials, and carefully deliver the products to the point of sale. For example, Singapore Airlines provides larger seats. 5) Design differentiation strategy: emphasis on design and development, providing truly different things, breaking past advantages. 6) No differentiation strategy: Aiming at the mass market, creating a category economy, providing only slight differences.

The last is the category strategy driven by demand. Porter puts forward that category refers to the goal of strategy focus and analyzes the relationship between differentiation and cost leadership, finds out the target market, as well as applies corresponding strategies. Mainly including: 1) No partition strategy: Find out the public perception of products and use the mass marketing strategy. 2) Segmentation strategy: Identify possible areas, select divisions, and formulate strategies for target market segments. 3) Niche strategy: To serve specific goals well. Porter recommends that organizations strengthen a variety of foundations, such as products, channels, customers, or specific geographical areas. Use enhanced functions to meet specific niche market needs. 4) Differentiation strategy: Each of the differences is aimed at specific market subsegments. The products are diversified and produced in large quantities for the customers to choose.

\section{Niche Strategy and the Development of SMEs in China}

This paper proposes the Niche market opportunity, which aims to provide a practical and feasible strategic idea and method for small and medium-sized enterprises in China. Niche Strategy is very suitable for SMEs in China, mainly based on the following four aspects: First, the starting point of Niche Strategy is matched with the development of SMEs in China. SMEs have been regarded as weak enterprises and post enterprises, their development strategy is mainly to seek the gap market which is ignored by large enterprises. The main starting point of Niche Strategy is such small and medium-sized enterprises, so there is a matching relationship between them. Second, Niche Strategy is matched with the entrepreneurial spirit of the small and medium entrepreneurs, which is to be the leader of the market by capturing the Niche opportunities, so that the small and medium entrepreneurs use Niche Strategy. Third, Niche Strategy contributes to the formation of their specialization capabilities for SMEs. Niche Strategy is mainly to obtain the opportunity in small markets. Due to the special targeted demand, it is beneficial to SMEs to form professional ability, which is the foundation of enterprise's ability. Niche Strategy is conducive to the formation of rational strategic planning habits for SMEs, and this is also the starting point for SMEs' strategy.

As we all know, Niche Strategy, as a compound strategy, is based on specialization strategy. Aiming at Chinese SMEs, we can understand Niche as an enterprise growth strategy. Niche Strategy has applicability, feasibility and sustainability for SMEs. It has practical guiding effect on the sustainable growth of Chinese SMEs.

(1) Applicability. Applicability is to assess the degree of adaptation of the proposed strategy to the organizational situation identified in the strategic analysis. The key to estimate the applicability of a strategy to an organization, depends on whether the strategy can make full use of the advantages of the organization or the opportunity provided by the environment, whether it can improve the 
organization's competitive position and whether it is consistent with the organization's goals. The main body of the implementation of Niche Strategy is small and medium enterprises. The niche strategic enterprises choose one or more small subsegments of the industry as its niche business, and tailor their Niche Strategy to niche services instead of serving other markets.

(2) Feasibility. Feasibility refers to analyze whether enterprises can successfully implement strategies. The scope of changes proposed by the strategy should be affordable to the organization resources. No matter how strong the ability of management SMEs have, those large and long-living enterprises have more competitive advantages than SMEs in any industry. Their market is closely linked, and they have a strong status in the capital market and huge internal operation capital. Small and medium-sized enterprises cannot compete with large enterprises in terms of capital, technical manpower, scale or strength, and cannot compete positively with them. Enterprises using the niche strategy can avoid the positive conflict with the large enterprises and reduce the possibility of being strangled by the large enterprises in the dominant position in the early stages of development. At the same time, the niche market is generally abandoned or neglected by large enterprises, so the degree of market competition is low. (Tseng et al., 2015) [6].

(3) Sustainability. Growth reflects the improvement of business ability or value-added ability. Sustainability means that the promotion of business ability is not a short-term or accidental phenomenon, but a long-term trend. Niche Strategy is a specialized strategy that chooses to concentrate and dig deeply. It not only solves the problem of the survival of small and medium enterprises, but also improves the ability of all aspects of the enterprise on this basis: First, the niche market of the enterprise is from the local to the whole country then to the whole world, which provides a broad space for the growth of the enterprise; secondly, the gain of the niche market of the enterprise depends on the high quality of the enterprise products and the sustainable low cost, not on certain special factors, thus it has the sustainability.

\section{Conclusion}

In order to capture niche opportunities and to seize the opportunity, when small and medium-sized enterprises identity the overseas market that other large enterprises ignore, they will build factories abroad through various means to build overseas factories and expand advertising to achieve "predominance" advantage. But for the gap market or other overseas opportunities ignored by the large enterprises, small and medium-sized enterprises will implement joint venture strategy or establish sole proprietorship according to the actual situation of the enterprise. These strategies can well ensure that niche opportunities are firmly in the hands of small and medium-sized enterprises. However, it is necessary to explain that small and medium sized enterprises are likely to attract the attention of large enterprises or major competitors after obtaining profits by capturing the niche market opportunities. At that time, small and medium-sized enterprises must rapidly expand capacity based on this opportunity and realize economies of scale, in order to reduce costs, so that they can have a firm foothold and achieve development in niche markets.

\section{Acknowledgement}

The authors would like to thank NSFC (No. 11701209), the Project of Science and Technology Development Plan for Jilin Province (No.20160520110JH) and Science and Technology Research Project of Jilin Provincial Department of Education of China (JJKH20180462KJ,2015162) for financially supporting this research.

\section{References}

[1] Akgün A E, Byrne J C, Lynn G S, et al. New product development in turbulent environments: Impact of improvisation and unlearning on new product performance. Journal of Engineering and technology Management, 24( 2007)203-230. 
[2] Anna-Maija Nisula, Aino Kianto. Stimulating organisational creativity with theatrical improvisation. Journal of Business Research, 85(2018) 484-493

[3] Kale P, Dyer J H, Singh H. Alliance capability, stock market response, and long - term alliance success: the role of the alliance function. Strategic management journal, 23(2002)747-767.

[4] Patel P C, Terjesen S. Complementary effects of network range and tie strength in enhancing transnational venture performance. Strategic Entrepreneurship Journal, 5(2011)58-80.

[5] Reymen I M M J, Andries P, Berends H, et al. Understanding dynamics of strategic decision making in venture creation: a process study of effectuation and causation. Strategic entrepreneurship journal, 9(2015)351-379.

[6] Tseng H L, Lee Y C, Chu P Y. Improvisational Capabilities in e-Commerce Adoption: A Multiyear Comparison. Journal of Global Information Technology Management (Ivy League, 18(2015)48-66. 